\title{
Carreira e remuneração do magistério público da educação básica no sistema de ensino estadual de Santa Catarina
}

\author{
Marcos Edgar Bassi
}

marcos.e.bassi@gmail.com

Andréia Debovi

andreiadebovi@branet.com.br

\author{
Nádia Maria Soares Sandrini ${ }^{3}$ \\ nadia.sandrini@unisul.br
}

\begin{abstract}
Resumo
$\mathrm{O}$ direito à carreira e à remuneração justa para o magistério público da educação básica tornou-se, ao longo dos últimos anos, um tema permanente, na pauta nacional, em defesa do reconhecimento social e da valorização da categoria. O presente artigo descreve aspectos da carreira do magistério público da educação básica da rede estadual de ensino de Santa Catarina e evidencia como ela se constitui e se compõe. Os dados aqui discutidos fazem parte da pesquisa "Remuneração dos professores das escolas públicas de educação básica: configurações, impactos, impasses e perspectivas", vinculada ao Observatório da Educação, programa do Ministério da Educação, realizada por vários autores. Caracteriza-se como uma pesquisa documental que tomou como referência a legislação estadual que foi obtida por meio das páginas eletrônicas do Governo do Estado de Santa Catarina. Percebeu-se o baixo valor do vencimento básico em paralelo a um conjunto de vantagens pecuniárias como
\end{abstract}

1 Doutor em Educação pela Pontifícia Universidade Católica de São Paulo, Brasil (2001). Professor da Universidade Federal do Paraná, Brasil.

2 Pedagoga pela Universidade do Sul de Santa Catarina, Brasil (2012).

3 Mestre em Educação pela Universidade do Sul de Santa Catarina, Brasil (2000). Professor titular da Universidade do Sul de Santa Catarina, Brasil. 
gratificações e prêmios. Essas vantagens elevam o valor da remuneração final, mas encobrem mecanismos de desvalorização e de precarização do trabalho docente. $\mathrm{O}$ quadro de precarização se agrava com a existência de um número elevado de professores admitidos em caráter temporário que, apesar dos contratos garantirem os mesmos componentes de remuneração, não ingressam e não têm acesso a movimentação na carreira.

Palavras-chave: Educação básica; Magistério público; Remuneração docente; Carreira docente.

\section{Introdução}

A compreensão das regras que regem a carreira do magistério público da educação básica é essencial para a análise da remuneração dos professores, objetivo básico da pesquisa "Remuneração dos professores das escolas públicas de educação básica: configurações, impactos, impasses e perspectivas", vinculada ao Observatório da Educação, programa do Ministério da Educação (MEC). Nesse âmbito, o presente artigo descreve aspectos do magistério público da educação básica da rede estadual de ensino de Santa Catarina especificamente relacionados à remuneração e à carreira atualmente em vigência.

A legislação que serviu de referência para esse estudo foi obtida por meio de pesquisa documental às páginas eletrônicas do Governo do Estado de Santa Catarina ${ }^{4}$. A seleção dos itens e das informações descritos ao longo do artigo foi efetivada após o preenchimento de um instrumento de coleta de dados aplicado aos participantes da pesquisa mencionada.

As referências legais e jurídicas que normatizam e organizam a carreira dos servidores públicos, de modo geral, e do magistério público, em especial, podem ser, segundo a literatura especializada (DUTRA JR. et al., 2000), de três tipos: (1) uma única lei pode dispor, conjuntamente, sobre o estatuto dos servidores públicos e sobre o plano de carreira do magistério; (2) o estatuto e o plano de carreira podem estar, cada um, dispostos em leis específicas; e ainda (3) o estatuto pode ser único para os servidores

4 Em especial, os sites da Assembleia Legislativa do Estado de Santa Catarina (ALESC) e da Procuradoria Geral do Estado de Santa Catarina. 
públicos, nele incluso o magistério, e, em lei exclusiva, o plano de carreira do magistério. No âmbito da rede estadual em questão, a regulação da carreira do magistério está vinculada a três instrumentos legais: ao Estatuto dos Funcionários Públicos, ao Estatuto do Magistério e ao Plano de Carreira. Convém, a propósito, transcrever a definição de alguns desses termos relacionados à carreira apresentada por Dutra Jr. et al. (2000):

O estatuto corresponde ao conjunto de normas que regulam a relação funcional dos servidores com a administração pública, e dispõe, por exemplo, sobre investidura, exercício, direitos, vantagens, deveres e responsabilidades.

Já o plano de carreira consiste no conjunto de normas que definem e regulam as condições e o processo de movimentação dos integrantes em uma determinada carreira, e estabelece a progressão funcional e a correspondente evolução da remuneração. Por sua vez, carreira constitui-se na organização dos cargos de determinada atividade profissional em posições escalonadas em linha ascendente. (DUTRA JR. et al., 2000, p. 36, grifo nosso).

Após essa breve introdução, o artigo prossegue com a descrição de aspectos da carreira relacionados à remuneração do magistério público da rede estadual de ensino de Santa Catarina enfocando tanto os professores efetivos, como os professores admitidos em caráter temporário. Uma última seção é reservada às considerações finais.

\section{A carreira no magistério público estadual de Santa Catarina}

Desde 1986, a carreira no magistério público estadual é regulada pela Lei n. 6.844, que dispõe sobre o Estatuto do Magistério Público Estadual (SANTA CATARINA, 1986). Essa Lei substituiu o estatuto anterior, fixado pela Lei n. 5.205, de $1975^{5}$, que, por sua vez, havia revogado as Leis

5 Alterada parcialmente pelas Leis: n. 5.230/76; n. 5.294/76; n. 5.309/77; n. 5.361/77; n. 5.394/77; n. 5.524/79; n. 5.663/80; n. 5.505/78; n. 5.527/79 (art. 134); n. 5.665/80; n. 5.701/80; n. 5.750/80; n. $5.848 / 80 ;$ n. 5.850/81 (art. 24); n. 5.851/81 (art. 137); n. 6.046/82; n. 6.089/82 (art. 84); n. 6.110/82; n. 6.172/82; n. 6.219/83; n. 6.400/84; n. 6.455/84; n. 6.707/85. Revogada parcialmente pela Lei n. 6.032/82 e totalmente pela Lei n. 6.844/86. 
n. 2.293, de 1960, e n. 2.942, de 1961. Historicamente, a regulamentação e as alterações estatutárias do magistério estadual seguiram os respectivos cenários de reformas de ensino e diretrizes nacionais, não sendo diferente com o estatuto atualmente em vigência ${ }^{6}$.

As normativas de carreira do magistério estadual também são definidas no Plano de Cargos e Carreira da categoria, que está regulamentado pela Lei Complementar Promulgada n. 1.139 (LCP1139) (SANTA CATARINA, 1992a), na qual foi fixado a nova sistemática de vencimentos e instituído gratificações. A LCP1139 revogou, na íntegra, a Lei Complementar n. 49 (LC49) (SANTA CATARINA, 1992b), que havia inicialmente instituído o Plano de Cargos, Carreiras e Vencimentos do Magistério Público Estadual, mas que ficou em vigor por apenas seis meses.

Formavam o quadro do magistério público do estado, até 1992, os cargos de Docente e de Especialista em Assuntos Educacionais. Em 1992, a LC49 substituiu o cargo de Docente pelo de Professor e criou os cargos de Consultor Educacional e de Assistente Técnico-Pedagógico. Todos foram mantidos pela LCP1139 que, inclusive, facultou aos professores e especialistas em assuntos educacionais, lotados e/ou em exercício em órgãos de administração da Secretaria de Estado da Educação, Cultura e Desporto na data da publicação da LC49, o enquadramento no cargo de consultor educacional e assistente técnico-pedagógico nos níveis e referências atuais. Todos esses cargos são de provimento efetivo e são classificados em níveis e referências com atribuições e habilitações profissionais estabelecidas na Lei.

Em 2005, a Lei Complementar n. 287 (LC287) (SANTA CATARINA, 2005) criou o cargo de Assistente de Educação, transformando para isto parte dos cargos vagos de Professor 7 . Definiu para o seu exercício a habilitação para o magistério, obtida tanto em nível médio quanto em nível

6 Alterada parcialmente pelas Leis: n. 6.901/86;n. 1.114/88;n. 7.373/88;n. 1.139/92;n. 38/91;n. 47/92;n. 48/92; n. 49/92; n. 128/94; n. 9.751/94; n. 9.832/95; n. 14.406/08; n. 457/09; n. 36/91; n. 43/92; n. 53/92; n. 67/92; n. 9.847/95; n. 10.287/96; n. 264/04; n. 284/05; n. 421/08; n. 487/2010. Revogada parcialmente pelas Leis: n. $36 / 91$ (arts. $4^{\circ}$ e 80 ); n. $49 / 92$ (arts. $7^{\circ}, 8^{\circ}, 9^{\circ}, 16,33,3435,37,38,40,41,42$ e 49 ) e n. $421 / 08$ (\$ $2^{\circ}$ do art. 82 e o art. 86); n. 491/ 2010 (arts. 181 a 195). Regulamentada pelos Decretos: $n$. 30876 (19/11/86); n. 2783 (15/12/88); n. 2652 (23/9/92); n. 660 (30/01/96); n. 1108 (28/11/03); n. 2266 (29/07/04).

7 Ao ser promulgada, a LCP 1139 estabeleceu inicialmente 40.000 cargos para Professor. Em 2005, duas leis complementares transformaram 2.500 desses cargos em cargos de Assistente de Educação e outros 3.500 em cargos de Assistente Técnico-Pedagógico. 
superior. Segundo a LC287, esses profissionais ocupariam gradativamente, por concurso público, as funções gratificadas de responsável pelas secretarias das escolas, historicamente exercidas por profissionais do quadro do magistério público que se afastavam do seu cargo efetivo para exercerem esse papel, indicados pelo chefe do poder executivo a título de função gratificada. Enquanto perdurasse o seu afastamento, suas vagas permaneciam devidamente vinculadas aos seus nomes e, temporariamente, eram ocupadas por professores Admitidos em Caráter Temporário (ACT).

A propósito, e por fim, é importante reservar espaço, nessa descrição, para os professores ACTs, particularmente devido à substancial proporção que, há pelo menos quatro décadas, vêm ocupando no exercício da docência. A legislação sobre esse tipo de contrato retroage a 1973, com a edição da Lei n. 4.886 que previa a designação "de professores a título precário e em caráter suplementar [...] para ministrar aulas excedentes em estabelecimento de ensino oficial, antes de ter sido aprovado em concurso público de provas ou de provas e títulos [...]" (SANTA CATARINA, 1973). Atualmente, a contratação de professores ACTs, após várias alterções, é regulada pela Lei Complementar n. 456 (SANTA CATARINA, 2009).

Com relação ao número de professores, dados de março de 2011, da Diretoria de Desenvolvimento Humano, órgão da Secretaria do Estado da Educação, contabilizavam 21.979 professores efetivos e 16.370 professores ACTs, os quais representam, portanto, 43\% dos professores da educação básica estadual.

A jornada ou o regime de trabalho semanal dos professores estaduais está dividido em 10 (dez), 20 (vinte), 30 (trinta) e 40 (quarenta) horas semanais, de acordo com a carga horária curricular da unidade escolar. A jornada dos demais cargos do magistério é, diferentemente, realizada em 20 (vinte) e 40 (quarenta) horas semanais. No caso específico dos professores que atuam na área de educação infantil, nos Centros de Educação Infantil, o regime é de 40 (quarenta) horas semanais, sendo 30 horas em regência de classe, cumpridas em uma jornada de trabalho de 06 (seis) horas diárias e contínuas, e as demais em horas-atividade a serem cumpridas na unidade escolar, conforme o planejamento das atividades curriculares. 
Na composição da jornada de trabalho dos professores (efetivos ou ACTs) dos anos finais do ensino fundamental e do ensino médio, $20 \%$ destinam-se a horas-atividade relativas ao trabalho extraclasse e às atividades complementares à regência de classe. Devem ser cumpridas, obrigatoriamente, segundo o plano de cargos e carreiras, na unidade escolar (TAB. 1). Desse modo, para uma jornada de 40 horas-aula semanais, 32 horas-aula devem ser trabalhadas em sala de aula enquanto as outras 8 devem ser usufruídas em horas-atividade. A mesma proporção $(20 \%)$ se repete para as outras jornadas, exceto para a do magistério da educação infantil, conforme ressalvado acima.

TABELA 1

Composição da jornada de trabalho horas-aula e horas-atividade

\begin{tabular}{c|c|c}
\hline JORNADA DE TRABALHO & HORAS-AULA & HORAS-ATIVIDADE \\
\hline 40 & 32 & 8 \\
30 & 24 & 6 \\
20 & 16 & 4 \\
10 & 8 & 2 \\
\hline
\end{tabular}

Fonte: SANTA CATARINA, 1992a, com elaboração dos autores.

O plano de carreira estadual estabelece uma peculiaridade relacionada às horas-atividade que faculta aos professores a possibilidade de ministrarem aulas acima do mínimo estabelecido na jornada em sala até o limite das horas-atividade, estimuladas por um ligeiro acréscimo monetário à remuneração. Assim, aquele número de horas-atividade proporcional a cada uma das jornadas pode ser acrescido à jornada como ministração de aulas na forma de aulas excedentes. Dessa forma, o professor com jornada de 40 horas semanais poderá assumir e ministrar até 8 horas-aula a mais e, para cada uma, receberá um valor adicional correspondente a 2,5\% calculado sobre o vencimento do cargo efetivo; para o professor com jornada de 30 horas-aula, até 6 aulas excedentes podem ser ministradas com percentual de $3,33 \%$ para cada uma; para a jornada de 20 horas-aula, até 4 aulas excedentes com percentual de 5\% cada uma e para a jornada de 10 horas-aula, até 2 aulas excedentes com acréscimo percentual de $10 \%$ para cada uma (TAB. 2): 
TABELA 2

Correlação entre jornada de trabalho, acréscimo de aulas excedentes e percentual de acréscimo ao vencimento básico por aula excedente

\begin{tabular}{|c|c|c|c|c|c|c|c|}
\hline \multicolumn{2}{|c|}{$\begin{array}{c}\text { JORNADA } \\
\text { DE } 40 \text { h/a }\end{array}$} & \multicolumn{2}{|c|}{$\begin{array}{c}\text { JORNADA } \\
\text { DE } 30 \mathrm{~h} / \mathrm{a}\end{array}$} & \multicolumn{2}{|c|}{$\begin{array}{l}\text { JORNADA } \\
\text { DE } 20 \text { h/a }\end{array}$} & \multicolumn{2}{|c|}{$\begin{array}{c}\text { JORNADA } \\
\text { DE } 10 \text { h/a }\end{array}$} \\
\hline $\begin{array}{l}\text { Horas-aula } \\
\text { excedentes }\end{array}$ & $\begin{array}{c}\% \text { de } \\
\text { acréscimo }\end{array}$ & $\begin{array}{l}\text { Horas-aula } \\
\text { excedentes }\end{array}$ & $\begin{array}{c}\% \text { de } \\
\text { acréscimo } \\
\text { por aula }\end{array}$ & $\begin{array}{l}\text { Horas-aula } \\
\text { excedentes }\end{array}$ & $\begin{array}{c}\% \text { de } \\
\text { acréscimo } \\
\text { por aula }\end{array}$ & $\begin{array}{l}\text { Horas-aula } \\
\text { excedentes }\end{array}$ & $\begin{array}{c}\% \text { de } \\
\text { acréscimo } \\
\text { por aula }\end{array}$ \\
\hline $\begin{array}{l}1 \\
2 \\
3 \\
4 \\
5 \\
6 \\
7 \\
8\end{array}$ & $\begin{array}{c}2,5 \\
5 \\
7,5 \\
10 \\
12,5 \\
15 \\
17,5 \\
20\end{array}$ & $\begin{array}{l}1 \\
2 \\
3 \\
4 \\
5 \\
6\end{array}$ & $\begin{array}{c}3,33 \\
6,66 \\
10 \\
13,33 \\
16,66 \\
20\end{array}$ & $\begin{array}{l}1 \\
2 \\
3 \\
4\end{array}$ & $\begin{array}{c}5 \\
10 \\
15 \\
20\end{array}$ & $\begin{array}{l}1 \\
2\end{array}$ & $\begin{array}{l}10 \\
20\end{array}$ \\
\hline
\end{tabular}

Fonte: SANTA CATARINA, 1992a, com elaboração dos autores.

Nota: Os percentuais de 3,33\% para cada aula excedente da jornada de 30 horas-aula, de $5 \%$ para a jornada de 20 horas-aula e o de $10 \%$ para a jornada de 10 horas-aula foram calculados de forma a preservar o mesmo valor gerado pelo cálculo de 2,5\% por aula-excedente sobre o vencimento do cargo efetivo.

Além desse estímulo à ministração de aulas, que acaba distorcendo a carreira no que se refere ao tempo previsto para o planejamento da atuação docente, o plano de carreira possibilita a incorporação aos proventos da aposentadoria do valor médio pago às aulas excedentes ministradas nos três últimos anos de trabalho efetivo.

Na escolha dessas aulas excedentes, é dada prioridade ao professor que contar com maior tempo de serviço no magistério público estadual e, havendo empate, àquele que tiver maior tempo de serviço na unidade escolar. Cabe ressaltar que as aulas excedentes não substituem as horasatividade, mas certamente tornam estas ainda mais difíceis de serem cumpridas no seu propósito original.

As aulas excedentes e a contratação em grande número de professores ACTs parecem ter se transformado, ao longo do tempo, em estratégias levadas a cabo pelo governo estadual para conter ou reduzir os gastos com educação e contornar a realização de concursos públicos para professores, os quais não ocorrem desde 2005. As aulas deixadas 
em aberto pela redução do quadro efetivo, seja pelo afastamento de professores decorrente de licenças, seja pelo aumento do número de aposentadorias, vêm sendo transformadas em aulas excedentes, que deveriam originalmente cobrir apenas as situações emergenciais como as licenças mencionadas e a ampliação da rede de ensino, até a realização do concurso e ingresso de novos professores efetivos.

Quanto à formação e à atuação dos professores, o Quadro 1 informa a habilitação requerida e as respectivas áreas de atuação definidas para a educação básica estadual. Assim, o professor com formação em magistério de médio está habilitado a atuar nas áreas 1, 4, 5 e 6 que correspondem, respectivamente, às séries iniciais do ensino fundamental, à educação infantil, à educação especial e à educação de jovens e adultos:

\section{QUADRO 1}

Correspondência entre formação e atuação dos professores

\begin{tabular}{c|c|c}
\hline HABILITAÇÃO & $\begin{array}{c}\text { ÁREA DE } \\
\text { ATUAÇÃO }\end{array}$ & $\begin{array}{c}\text { NÍVEL / MODALIDADE } \\
\text { DE ENSINO } \\
\text { CORRESPONDENTE }\end{array}$ \\
\hline $\begin{array}{c}\text { Magistério em nível médio; } \\
\text { Licenciatura Plena; Pós-Graduação }\end{array}$ & 1 & $\begin{array}{c}\text { Ensino Fundamental } \\
-1^{\mathrm{a}} \text { a } 4^{\mathrm{a}}\end{array}$ \\
\hline $\begin{array}{c}\text { Licenciatura Curta; Licenciatura } \\
\text { Plena; Pós-Graduação }\end{array}$ & 2 & $\begin{array}{c}\text { Ensino Fundamental } \\
-5^{\mathrm{a}} \text { a } 8^{\mathrm{a}}\end{array}$ \\
\hline $\begin{array}{c}\text { Licenciatura Plena; Pós-Graduação } \\
\text { Magistério em nível médio; }\end{array}$ & 3 & $\begin{array}{c}\text { Ensino Médio } \\
\text { Licenciatura Plena; Pós-Graduação }\end{array}$ \\
\hline $\begin{array}{c}\text { Magistério em nível médio; } \\
\text { Licenciatura Curta; Licenciatura } \\
\text { Plena; Pós-Graduação }\end{array}$ & 4 & $\begin{array}{c}\text { Educantil } \\
\text { Educação Especial }\end{array}$ \\
\hline $\begin{array}{c}\text { Magistério em nível médio; } \\
\text { Licenciatura Curta; Licenciatura } \\
\text { Plena; Pós-Graduação }\end{array}$ & 6 & \begin{tabular}{c} 
Educação de \\
\hline
\end{tabular}
\end{tabular}

Fonte: SANTA CATARINA, 1992a, com elaboração dos autores.

Nota: A habilitação em Pós-Graduação compreende as formações em especialização, mestrado ou em doutorado. 
Muito embora o Plano de Cargos e Carreira da categoria preveja a existência de professores habilitados de ensino médio, o seu número é reduzido, particularmente devido a sua atuação estar restrita às etapas da educação infantil, responsabilidade dos municípios, e das séries iniciais do ensino fundamental que, no caso de Santa Catarina, encontra-se municipalizado. No caso da formação de licenciatura curta, há um contingente pequeno de professores com essa formação. Segundo dados da Secretaria de Educação, dos 21.979 professores efetivos na rede estadual no início de 2011, 84\% já tinham Pós-Graduação (17.244 com especialização, 965 com mestrado e 154 com doutorado), 13\% com licenciatura plena (2.882), apenas 1\% com licenciatura curta (140) e 3\% com magistério de ensino médio (594) (SANTA CATARINA, 2011).

No tocante à remuneração e à progressão na carreira, a TAB. 3 informa os valores dos vencimentos básicos, conforme a posição em níveis e referências, para os professores habilitados com ensino médio, com graduação (licenciatura plena) e com pós-graduação, essa última dividida em especialização, mestrado e doutorado. É possível simular, com base nesses valores e nas regras estabelecidas no plano de carreira, exemplos de progressão, dentro da mesma habilitação e com a incorporação de novas habilitações: 
TABELA 3

Vencimentos básicos do magistério público estadual para uma jornada de 40 horas semanais - Agosto, 2010

\begin{tabular}{|c|c|c|c|c|c|c|c|c|}
\hline \multirow{2}{*}{ HABILITAÇÃO } & \multicolumn{8}{|c|}{ REFERÊNCIAS } \\
\hline & NÍVEL & A & B & C & D & $\mathrm{E}$ & $\mathrm{F}$ & G \\
\hline \multirow{3}{*}{$\begin{array}{l}\text { Habilitação específica de magistério, } \\
\text { obtida em curso de Ensino Médio. }\end{array}$} & 1 & 609,46 & 626,22 & 643,51 & 661,12 & 679,35 & 697,98 & 717,19 \\
\hline & 2 & 661,12 & 679,35 & 697,98 & 747,12 & 736,92 & 757,22 & 778,00 \\
\hline & 3 & 717,19 & 736,92 & 757,22 & 778,00 & 799,36 & 821,40 & $p 843,96$ \\
\hline \multirow{2}{*}{ HABILITAÇÃO } & \multicolumn{8}{|c|}{ REFERÊNCIAS } \\
\hline & NÍVEL & A & B & C & D & $\mathrm{E}$ & $\mathrm{F}$ & G \\
\hline \multirow{3}{*}{$\begin{array}{l}\text { Habilitação obtida em curso de nível } \\
\text { superior, de duração plena, na área do } \\
\text { magistério com registro no MEC. }\end{array}$} & 7 & $\bullet^{993,12}$ & 1020,48 & 1048,55 & 1077,37 & 1107,00 & 1137,46 & 1168,67 \\
\hline & 8 & 1077,37 & 1107,00 & 1137,46 & 1168,62 & 1200,89 & 1233,89 & 1267,77 \\
\hline & 9 & 1168,67 & 1200,89 & 1233,89 & 1267,77 & 1302,68 & 1338,44 & 1375,33 \\
\hline \multirow{2}{*}{ HABILITAÇÃO } & \multicolumn{8}{|c|}{ REFERÊNCIAS } \\
\hline & NÍVEL & A & B & C & D & E & $\mathbf{F}$ & G \\
\hline ESPECIALIZAÇÃO & 10 & 1267,77 & 1302,68 & 1338,44 & 1375,33 & 1413,13 & 1452 & $P_{1491,93}$ \\
\hline MESTRADO & 11 & 1375,33 & 1413,13 & 1452,00 & 1491,93 & 1532,95 & 1575,11 & 1618,43 \\
\hline DOUTORADO & 12 & 1491,93 & 1532,95 & 1575,11 & 1618,43 & 1662,92 & 1708,63 & 1755,66 \\
\hline
\end{tabular}

Fonte: SANTA CATARINA. Secretaria de Estado de Educação (2011), com elaboração e grifos dos autores.

Notas: (1) A setas representam a progressão na carreira. As cores, a conquista de referências e vencimentos a cada intervalo de tempo estabelecido no plano. (2) Foi omitida a tabela salarial de níveis 4 a 6, relativa à habilitação de Licenciatura Curta.

O progresso funcional do membro do magistério estável, regulamentado pelo Chefe do Poder Executivo, ocorre nas formas horizontal e vertical, pela conquista de referências e níveis. O progresso funcional horizontal ocorre a cada 03 (três) anos, no mês de aniversário do funcionário, podendo este conquistar 01 (uma) referência pela comprovação de tempo de serviço e 01 (uma) pelo alcance de desempenho satisfatório no exercício do cargo, no qual será considerada também a frequência e/ou ministração de aulas em cursos de aperfeiçoamento e atualização. A progressão funcional vertical ocorre de duas formas: (1) dentro da mesma habilitação para o 
nível seguinte e em referência de vencimento imediatamente superior, observando os critérios da progressão horizontal quando o professor alcançar a última referência; (2) para o nível correspondente à nova habilitação e em referência de vencimento imediatamente superior. Essa progressão poderá estar condicionada a mudanças ou não de área de ensino, disciplina, formação, atuação ou local de trabalho e se dará de dois em dois anos, por meio de processo de seleção, para preencher as vagas existentes. Sem esse condicionante, poderá ocorrer a qualquer tempo, mediante apresentação de nova habilitação adquirida.

A título de exemplo, pode-se simular a progressão funcional de um Assistente de Educação, último cargo criado para ingresso na carreira do magistério com titulação em nível médio. Ao ingressar, por meio de concurso público, no início do ano letivo de 2010, é enquadrado no plano de cargos no nível 1 referência A; permanecerá em estágio probatório por três anos e será considerado estável a partir de 2012. Em 2013, no mês de seu aniversário, esse servidor poderá requerer 1 referência pelos 3 anos de serviço e outra pela participação em cursos de educação continuada. Assim, ele passará para nível 1 referência $\mathrm{C}$ e, se permanecer com a mesma habilitação de nível médio, passará pelo mesmo processo a cada 3 anos caminhando no quadro da seguinte forma: em 2016 - 1E; 2019 - 1G; em 2022, esgotado o nível 1, na progressão horizontal, ele ou ela passará para o nível 2, na referência com vencimento imediatamente superior ao atual (considerando a TAB. 3, passará para - 2F); em 2025 - 3E; em 2028 - 3G. Portanto, no exemplo exposto, se o servidor tiver atendido os critérios estabelecidos, terá completado a trajetória na carreira na mesma habilitação em, pelo menos, 18 anos de efetivo exercício. O valor do vencimento de cada referência guarda entre si uma diferença percentual de $2,75 \%$ e o valor do vencimento final (3G ou 9G) é 38\% superior ao do inicial (1A ou 7A).

Ainda descrevendo as possíveis movimentações previstas, se considerarmos que o servidor concluiu sua Licenciatura Plena, poderá reivindicar sua progressão vertical, a qualquer tempo, com a apresentação da nova habilitação, pois não implicará em mudanças na sua área de atuação. Assim, passará do nível em que estiver na 
habilitação de ensino médio para a de nível 7 e, na referência, para a de vencimento imediatamente superior à que se encontrava até então.

A progressão do nível 7 aos 10, 11 ou 12 também se dará automaticamente, desde que a pós-graduação cursada esteja de acordo com o cargo ou área de atuação do funcionário. Pode-se, em tese, vislumbrar ainda uma espécie de atalho nesse processo de progressão funcional: esse mesmo Assistente de Educação, com o mesmo histórico de ingresso na carreira do magistério, com titulação em nível médio, se cursar uma licenciatura em pelo menos 4 anos, seguida de uma especialização em cerca de 2 anos, poderá requerer a progressão vertical primeiro para o nível 7A e depois para o nível 10A em 6 ou 7 anos. Com mais 9 anos de progressão horizontal nesse último nível, de acordo com as regras estabelecidas, atingirá o topo da tabela de vencimentos em 16 anos e com valores bem mais substanciais. Nessa trajetória, entre o vencimento inicial da primeira habilitação e a de graduação há uma diferença de 39\% e, entre esta e a da especialização, mais $22 \%$. Entre a primeira referência e a última considerada, $145 \%$. Parece significativo no que se refere à progressão e às referências conquistadas, contudo, essa trajetória mais rápida acaba encobrindo a realidade dos baixos valores dos vencimentos dos professores da rede estadual de ensino catarinense, cuja solução é contemporizada pela existência e acréscimo à remuneração final de vantagens pecuniárias, mais conhecidas como "penduricalhos", na forma de gratificações, adicionais, abonos e prêmios.

A propósito da menção a esses acréscimos, o Plano de Cargos e Carreira estadual, com seguidas alterações após sua promulgação em 1992, instituiu um conjunto de gratificações, relacionadas na TAB. 4, com os seguintes percentuais incidentes sobre o vencimento dos cargos efetivos: 
TABELA 4

Gratificações estabelecidas pelo Plano de Cargos e Carreira

\begin{tabular}{|c|c|c|}
\hline CARGO EFETIVO & GRATIFICAÇÃO PREVISTA & $\%$ \\
\hline Ensino Fundamental $-1^{\mathrm{a}}$ a $4^{\mathrm{a}}$ & \multirow{5}{*}{ Regência de classe } & 40 \\
\hline Educação Infantil & & 40 \\
\hline Educação Especial & & 40 \\
\hline Educação de Jovens e Adultos & & 40 ** \\
\hline (nivelamento e alfabetização) & & 25 * \\
\hline Ensino Fundamental $-5^{\mathrm{a}}$ a $8^{\mathrm{a}}$ & \multirow{2}{*}{ Ministração de aulas } & $25 *$ \\
\hline Ensino Médio & & $25 *$ \\
\hline Especialista em Assuntos Educacionais & \multirow{4}{*}{$\begin{array}{l}\text { Função especializada de } \\
\text { magistério }\end{array}$} & 25 * \\
\hline Consultor Educacional & & $25 *$ \\
\hline Assistente Técnico Pedagógico & & 25 * \\
\hline Assistente de Educação & & \\
\hline
\end{tabular}

Fonte: SANTA CATARINA, 1992a.

Notas: Assegurado aos servidores inativos que incorporaram, nos proventos de aposentadoria, as gratificações referentes ao efetivo exercício das funções do cargo.

* Assegurado aos membros do magistério que atuam nos órgãos central e descentralizados da Secretaria de Estado da Educação e nas Secretarias de Estado de Desenvolvimento Regional.

** O Professor de Educação de Adultos fará jus à gratificação referida desde que estejam matriculados e frequentando sua disciplina o mínimo de 50 (cinquenta) alunos, para carga horária de 20 (vinte) horas semanais ou 100 (cem) alunos para carga horária de 40 (quarenta) horas semanais.

Conforme se pode depreender da TAB. 4, um professor que atue nas séries iniciais do ensino fundamental, por exemplo, terá acrescido, ao seu vencimento básico, mais $40 \%$ a título de gratificação de regência de classe.

O Plano de Cargos e Carreira prevê que as gratificações serão suspensas caso o membro do magistério afaste-se das atividades inerentes ao seu cargo, exceto no caso de licença para tratamento de saúde, própria ou familiar, licença gestação, licença paternidade, licençaprêmio e férias, e serão incorporadas aos proventos da aposentadoria após 02 (dois) anos de percepção (SANTA CATARINA, 1992a).

Outra vantagem pecuniária estabelecida no Plano prevê o pagamento 
do Prêmio Assiduidade aos professores e especialistas em assuntos educacionais, desde que seja comprovada frequência de $100 \%$ (cem por cento) ao trabalho na unidade escolar. Seu valor é fixado em $80 \%$ (oitenta por cento) do vencimento do mês de dezembro do ano correspondente e pago no segundo mês subsequente ao do encerramento do ano letivo. Além disso, o membro do magistério tem direito a receber o equivalente a 100\% (cem por cento) do valor do vencimento do cargo, por mês de licença-prêmio não gozada e trabalhada, desde que de forma integral, não podendo ultrapassar a um período por ano (SANTA CATARINA, 1992a).

O Plano também institui a gratificação de permanência ao membro do magistério pela continuação no exercício do cargo após completar o interstício aposentatório ${ }^{8}$, correspondendo a $5 \%$ (cinco por cento) do valor do vencimento do cargo, por ano de exercício, até o limite de 5 (cinco) anos, incorporando-se aos proventos da aposentadoria. No que se refere à aposentadoria, o membro do magistério terá o seu vencimento fixado, quando da passagem para a inatividade, em índice resultante do cálculo da média da carga horária dos três últimos anos, que será apurado sobre os valores constantes da tabela de vencimento vigente, observados o cargo, nível e referência do servidor. Contará para isto, inclusive, a carga horária do período de afastamento para o exercício de cargo em comissão ou função de confiança no âmbito da administração pública estadual. O cálculo da remuneração para o professor com exercício acumulado de cargo efetivo e admitido em caráter temporário (ACT) computará também a média anual da carga horária referentes à admissão em caráter temporário, sendo que o somatório de cargas horárias do cargo efetivo e de ACT será considerado até o limite de 40 (quarenta) horas. O valor pago a título de aulas excedentes será incorporado aos proventos de aposentadoria, de acordo com a média das mesmas, verificada nos três últimos anos (SANTA CATARINA, 1992a).

Por fim, o governo estadual instituiu, em 2008, o Prêmio Educar, uma espécie de abono mensal com valores diferenciados aos membros ativos do magistério (SANTA CATARINA, 2008).

8 Interstício Aposentatório é o beneficio concedido ao membro do magistério com tempo de serviço completo e que permanece no exercício do cargo por até 5 anos, incorporando o direito de receber, para cada ano, $5 \%$ de seu vencimento. 
A relação de vantagens pecuniárias descrita e concedida aos membros do magistério estadual, bem como o montante que as gratificações acrescem ao valor do vencimento básico podem ser vistas como uma compensação ao baixo patamar em que este último tem permanecido.

A Secretaria Estadual de Educação tem completado, anualmente e ao longo das últimas duas décadas, o quadro de magistério das unidades escolares de suas rede de ensino com um número significativo de professores admitidos em caráter temporário, os professores ACTs.

Esse tipo de contratação temporária de professores encontra respaldo na Constituição Federal de 1988 (CF88) e na legislação específica estadual. Apesar de a CF88 vedar o ingresso no serviço público por outro meio que não por concurso público (inciso II do art. 37), ela permite a contratação de servidores, por tempo determinado, desde que, conforme dispõe o inciso IX do art. 37, " para atender necessidade temporária de excepcional interesse público" (BRASIL, 1988).

Em Santa Catarina, a Lei Complementar n. 456 (LC456) regulamenta, no âmbito da rede estadual, essa norma constitucional (SANTA CATARINA, 2009). Pode-se questionar o argumento da excepcionalidade desse tipo de contrato na educação por acabar delongando a realização de concurso público para docentes, ainda mais diante do elevado número de ACTs em relação aos efetivos e à recorrência desse recurso ao longo das últimas décadas. A LC456 justifica, em 6 incisos, que a admissão dos ACTs, cujo período determinado de contratação não pode ultrapassar o do ano letivo, deve ocorrer exclusivamente para o exercício da docência nos casos de substituição aos afastamentos legais dos titulares; em virtude de existência de vaga não ocupada após a realização de concursos públicos; em decorrência de abertura de novas vagas, por criação ou por dispensa de seu ocupante; para atender as necessidades das escolas da rede pública estadual que atuam em tempo integral, no caso de projetos específicos; para desenvolver ações e programas operacionalizados pela Secretaria de Estado da Educação, reconhecidos pelo Conselho Estadual de Educação, executados em, pelo menos, $10 \%$ (dez por cento) das unidades escolares e voltados à melhoria do processo ensinoaprendizagem; e para atender as necessidades da Fundação Catarinense 
de Educação Especial ${ }^{9}$ (SANTA CATARINA, 2009). Essas justificativas ressaltam ainda mais o questionamento desse tipo de contrato, quando se constata que o Estatuto do Magistério Público de Santa Catarina previa somente um inciso para a contratação de professor substituto: para o caso de "vaga decorrente de afastamento temporário de professor titular" (SANTA CATARINA, 1975).

Entre as justificativas utilizadas pela Secretaria de Estado da Educação para realizar os contratos temporários com professores, em 2011, estão as seguintes: $62 \%$ decorreram de aulas excedentes, ou seja, de aulas existentes, mas não ocupadas pelos professores efetivos; $25 \%$ para cobrir vagas de afastamentos legais dos professores titulares; $9 \%$ decorrentes de projetos e programas específicos da Secretaria; e o percentual restante devido a aposentadorias e vagas não ocupadas por motivos não identificados (SANTA CATARINA, 2011).

Assim como para os professores efetivos, o regime de trabalho semanal do professor ACT poderá ser de 10 (dez), 20 (vinte), 30 (trinta) ou 40 (quarenta) horas semanais, conforme estiver disposto no edital do processo seletivo. Sua contratação poderá ocorrer em todas as áreas de ensino. Para cada uma delas, são definidas as habilitações necessárias e os respectivos códigos que relacionam os vencimentos dos ACTs com o quadro de carreira do magistério em que estão enquadrados os professores efetivos.

O vencimento dos professores ACTs é estabelecido a partir do vencimento inicial dos professores efetivos e pode variar proporcionalmente a depender da habilitação, do grau de formação e da área e/ou disciplina que o professor ACT está apto a atuar. A TAB. 5 reúne essa correlação e os vencimentos básicos correspondentes:

9 Órgão da Administração Direta estadual especializado na atenção à Educação Especial. 
TABELA 5

Correlação entre formação, atuação e vencimento básico dos professores ACTs

\begin{tabular}{|c|c|c|c|}
\hline HABILITAÇÃO & CÓDIGO & $\begin{array}{l}\text { REFERÊNCIA } \\
\text { (TAB. 3) }\end{array}$ & $\begin{array}{c}\text { VENCIMENTO } \\
\text { BÁSICO }\end{array}$ \\
\hline $\begin{array}{c}\text { Curso superior de duração } \\
\text { plena (licenciatura), na } \\
\text { disciplina específica }\end{array}$ & 300 & $7 \mathrm{~A}$ & 993,12 \\
\hline $\begin{array}{l}\text { Curso superior de curta } \\
\text { duração (licenciatura), na } \\
\text { disciplina específica }\end{array}$ & 200 & $4 \mathrm{~A}$ & 778,01 \\
\hline $\begin{array}{l}\text { Curso superior completo } \\
\text { em área técnica especifica }\end{array}$ & 150 & $90 \%$ de $7 \mathrm{~A}$ & 893,85 \\
\hline $\begin{array}{l}\text { Ensino Médio } \\
\text { (sem habilitação) }\end{array}$ & 100 & $70 \%$ de $7 \mathrm{~A}$ & 700,18 \\
\hline $\begin{array}{l}\text { Curso de Magistério - } \\
\text { Ensino Médio }\end{array}$ & 30 & $1 \mathrm{~A}$ & 609,46 \\
\hline $\begin{array}{l}\text { Sem habilitação em } \\
\text { Magistério de Ensino } \\
\text { Médio }\end{array}$ & 10 & $90 \%$ de $1 \mathrm{~A}$ & 548,49 \\
\hline
\end{tabular}

Fonte: SANTA CATARINA (2009), com elaboração dos autores.

Para além do vencimento básico, a remuneração mensal dos professores ACTs é acrescida das mesmas gratificações, auxílios, abonos e prêmios concedidos aos professores efetivos, tais como gratificações de regência, auxílio-alimentação, salário-família, gratificação natalina, abonos pelo exercício da docência, férias proporcionais, prêmio educar, prêmio assiduidade, entre outros. Contudo, na medida em que não ingressam na carreira, não progridem nas referências. Isto faz com que a remuneração final dos professores ACTs pemaneça muito inferior à dos efetivos. Como compensação para a precariedade desse tipo de contrato, a legislação estabelece que o tempo de serviço prestado pelo professor ACT seja considerado, como título, para ingresso no serviço público estadual e seja computado para os demais efeitos previstos em lei (SANTA CATARINA, 2009). 


\section{Considerações finais}

A descrição de aspectos da legislação específica que rege a carreira do magistério público estadual de Santa Catarina no que se refere à sua remuneração permitiu evidenciar como ela se constitui e se compõe. Sobressaiu-se o baixo valor do vencimento básico em paralelo a um conjunto de vantagens pecuniárias, como gratificações e prêmios, que, se de um lado, elevam o valor da remuneração final, por outro, encobrem os mecanismos de desvalorização e de precarização por que vêm passando o magistério público.

Completa esse quadro a existência de um número elevado de professores ACTs que, apesar de seus contratos assegurarem acesso aos mesmos componentes de remuneração, não ingressam na carreira docente e consolidam o processo de desvalorização e de precarização.

Como dito na introdução, a descrição antecede e permite a realização de análises mais consistentes e aprofundadas quanto aos seus condicionantes na perspectiva de poder contribuir para a implementação de políticas públicas que efetivamente promovam a valorização do magistério público tanto em Santa Catarina quanto no Brasil. 


\section{Referências}

BRASIL. Constituição (1988). Constituição da República Federativa do Brasil. Brasília, DF: Senado Federal, 1988.

. Emenda Constitucional n. 14 de 12 de setembro de 1996.

Modifica os arts. 34, 208, 211 e 212 da Constituição Federal e dá nova redação ao art. 60 do Ato das Disposições Constitucionais Transitórias. Brasília, 1996a. Disponível em: <http://www.planalto. gov.br/ccivil_03/constituicao/emendas/emc/emc14.htm>. Acesso em: 31 jan. 2011.

. Emenda Constitucional n. 53 de 19 de dezembro de 2006. Dá nova aos arts. $7^{\circ}, 23,30,206,208,211$ e 212 da Constituição Federal e ao art. 60 do Ato das Disposições Constitucionais Transitórias. Brasília, 2006. Disponível em: <http://www.planalto.gov.br/ ccivil_03/constituicao/emendas/emc/emc53.htm>. Acesso em: 31 jan. 2011.

. Lei n. 9.394 de 20 de dezembro de 1996. Estabelece as diretrizes e bases da educação nacional. Brasília, 1996b. Disponível em: <http:/ / portal.mec.gov.br/arquivos/pdf/ldb.pdf>. Acesso em: 24 abr. 2011.

. Lei n. 9.424 de 24 de dezembro de 1996. Dispõe sobre o Fundo de Manutenção e Desenvolvimento do Ensino Fundamental e de Valorização do Magistério, na forma prevista no art. 60, § $7^{\circ}$, do Ato das Disposições Constitucionais Transitórias, e dá outras providências. Brasília, 1996c. Disponível em: <http:/ / www. diariooficial.hpg.com.br/fed_lei_9424_1996.htm>. Acesso em: 31 jan. 2011.

. Lei n. 11.494 de 20 de junho de 2007. Regulamenta o Fundo de Manutenção e Desenvolvimento da Educação Básica e de Valorização dos Profissionais da Educação - FUNDEB, de que trata o art. 60 do Ato das Disposições Constitucionais Transitórias [...] e dá outras 
providências. Brasília, 2007. Disponível em:

< http://www010.dataprev.gov.br/sislex/paginas/42/2007/11494. htm>. Acesso em: 31 jan. 2011.

. Lei n. 11.172 de 9 de janeiro de 2001. Aprova o Plano Nacional de Educação e dá outras providências. Brasília, 2001. Disponível em: <http://www.planalto.gov.br/ccivil_03/leis/leis_2001/110172.htm>. Acesso em: 25 abr. 2011.

. Ministério da Educação. Conselho Nacional de Educação. Câmara de Educação Básica. Parecer n. 9, de 02 de abril de 2009. Revisão da Resolução CNE/CEB n. 3/97, que fixa Diretrizes para os Novos Planos de Carreira e de Remuneração para o Magistério dos Estados, do Distrito Federal e dos Municípios. Brasília, 2009a. Disponível em: <http:/ / www.crmariocovas.sp.gov.br/pdf/ diretrizes_p0317-0330_c.pdf>. Acesso em: 25 abr. 2011.

. Ministério da Educação. Conselho Nacional de Educação. Câmara de Educação Básica. Parecer n. 10 de 3 de setembro de 1997. Diretrizes para os Novos Planos de Carreira e de Remuneração do Magistério dos Estados, do Distrito Federal e dos Municípios. Brasília, 1997a. Disponível em: <http:/ / www.crmariocovas.sp.gov.br/pdf/ diretrizes_p0317-0330_c.pdf>. Acesso em: 25 abr. 2011.

. Ministério da Educação. Conselho Nacional de Educação. Câmara de Educação Básica. Resolução n. 2 de 28 de maio de 2009. Fixa as Diretrizes Nacionais para os Planos de Carreira e Remuneração dos Profissionais do Magistério da Educação Básica Pública [...]. Brasília, 2009b. Disponível em: <http:/ / portal.mec.gov.br/dmdocuments/ resolucao_cne_ceb002_2009.pdf>. Acesso em: 25 abr. 2011.

. Ministério da Educação. Conselho Nacional de Educação. Câmara de Educação Básica. Resolução n. 3 de 8 de outubro de 1997. Fixa diretrizes para Novos Planos de Carreira e de Remuneração para o Magistério dos Estados, do Distrito Federal e dos Municípios. 
Brasília, 1997b. Disponível em: <http:/ / portal.mec.gov.br/cne/ arquivos/pdf/1997/pceb010_97.pdf>. Acesso em: 09 nov. 10.

CAMARGO, Rubens Barbosa de et al. Financiamento da educação e remuneração docente: um começo de conversa em tempos de piso salarial. Revista Brasileira de Política e Administração da Educação, v. 25, n. 2, p. 341-363, mai./ago. 2009. Disponível em: <http://seer.ufrgs.br/ rbpae>. Acesso em: 30 ago. 11.

DUTRA JR. et al. Plano de carreira e remuneração do magistério público. Brasília: FUNDESCOLA/MEC, jan, 2000. Disponível em: <http:// www.dominiopublico.gov.br/pesquisa/DetalheObraForm.do?select_ action=\&co_obra=27456>. Acesso: 13 out. 2011.

FLORIANÓPOLIS. Lei n. 1.811 de 14 de setembro de 1981. Dispõe sobre o Estatuto do Magistério Público de Florianópolis. Florianópolis, 1981.

. Lei n. 2.915 de 19 de julho de 1988. Institui o plano de vencimentos e de carreira do Magistério Público Municipal e dá outras providências. Florianópolis, 1988.

OLIVEIRA, Dalila Andrade. A reestruturação do trabalho docente: precarização e flexibilização. Educação $\mathcal{E}$ Sociedade, Campinas, v. 25, n. 89, dez. 2004. Disponível em: <http:/ / www.scielo.br/scielo. php?script=sci_arttext\&pid=S0101-73302004000400003\&lng=pt\&nrm= iso>. Acesso em: 25 ago. 2011.

OLIVEIRA, Dalila Andrade. Política educacional e a re-estruturação do trabalho docente: reflexões sobre o contexto Latino-americano. Educação E Sociedade, Campinas, v. 28, n. 99, ago. 2007. Disponível em: <http:/ / www.scielo.br/scielo.php?script=sci_arttext\&pid=S010173302007000200004\&lng=pt\&nrm=iso >. Acesso em: 30 ago. 2011. 
SANTA CATARINA. Lei n. 4.886 de 29 de junho de 1973. Regula na parte referente ao exercício do magistério para regência de aulas das 5as, 6as, 7as e 8 as, séries do $1^{\circ}$ grau e para as do $2^{\circ}$ grau, o artigo 122, da Constituição do Estado. Disponível em: <http:/ /200.192.66.20/ alesc/docs/1973/4886_1973_lei\%20.doc>. Acesso 13 out. 2011.

. Lei n. 5.205 de 28 de novembro de 1975. Estatuto do Magistério Público de Santa Catarina. Florianópolis, 1975.

. Lei n. 6.844 de 29 de julho de 1986. Dispõe sobre o Estatuto do Magistério Público Estadual do Estado de Santa Catarina. Florianópolis, 1986. Disponível em: <http:/ / 200.192.66.20/alesc/ docs/1986/6844_1986_lei.doc>. Acesso: 23 ago. 2011.

. Lei Complementar Promulgada n. 1.139 de 28 de outubro de 1992. Dispõe sobre cargos e carreiras do Magistério Público Estadual estabelecem nova sistemática de vencimentos, institui gratificações e dá outras providências. Florianópolis, 1992a. Disponível em: <http:/ /200.192.66.20/alesc/docs/1992/1139_1992_lei_promulgada. doc>. Acesso: 18 ago. 2011.

. Lei Complementar n. 49 de 24 de abril de 1992. Dispõe sobre o novo Plano de Cargos, Carreiras e Vencimentos do Magistério Público Estadual, reformula a sistemática de Progressão Funcional, institui a Gratificação de Permanência, os Prêmios Mérito Gerencial e de Assiduidade e dá outras providências. Florianópolis, 1992b. Disponível em: <http:// 200.192.66.20/alesc/docs/1992/49_1992_ Lei_complementar.doc>. Acesso: 18 ago. 2011.

Lei Complementar n. 287 de 10 de março de 2005. Transforma cargos previstos na Lei n. 1.139, de 1992, e estabelece outras providências. Florianópolis, 2005. Disponível em: <http:/ / www.sed.sc.gov.br/ secretaria/documentos/cat_view/58-legislacao/185-ensino/76legislacao-estadual/82-leis?start=20>. Acesso em: 18 ago. 2011. 
. Lei n. 14.406 de 09 de abril de 2008. Concede Prêmio Educar aos servidores ativos ocupantes dos cargos de Professor, Especialista em Assuntos Educacionais, Assistente Técnico-Pedagógico e Assistente de Educação do Quadro do Magistério Público Estadual e aos Professores Admitidos em Caráter Temporário da Secretaria de Estado da Educação e da Fundação Catarinense de Educação Especial e estabelece outras providências. Florianópolis, 2008. Disponível em: <http://www.sed.sc.gov.br/secretaria/documentos/cat_view/58legislacao/185-ensino/76-legislacao-estadual/82-leis>. Acesso em: 13 out. 2011.

Lei Complementar n. 456 de 11 de agosto de 2009. Disciplina a admissão de pessoal por prazo determinado no âmbito do Magistério Público Estadual, para atender a necessidade temporária de excepcional interesse público, sob regime administrativo especial, nos termos do inciso IX do art. 37 da Constituição Federal. Disponível em: <http://200.192.66.20/alesc/docs/2009/456_2009_lei_complementar. doc>. Acesso: 13 out. 2011.

. Secretaria de Estado de Educação. ACT Quadro de Vagas 2011. Disponível em: <http://www.sed.sc.gov.br/secretaria/act/2011>. Acesso em: 13 out. 2011. 


\title{
Teaching carrier and remuneration in public education in the basic education sistem in the state of Santa Catarina
}

\begin{abstract}
The rights to a carrier and fair remuneration to the public teaching in the Basic Education has become, through last years, in a permanent theme in the national ruling in defense of social recognizing and category appreciation. This article describes some aspects of public teaching carrier in the basic education from statewide network in the State of Santa Catarina and it points how this is constituted. This research has been done in documents and the state law has been used as reference. The state law has been obtained from electronic pages from State of Santa Catarina Government. The instruments for data collection used to take described items were Position and Carrier Plans prepared to the research Public School Teacher Remuneration in Basic Education: settings, impacts, impasses and prospects. This research is bound to the Education Observatory, a program supported by MEC and performed by several authors. We perceived a low value of base-salary parallel to a number of pecuniary advantages such as bonus and prizes. These advantages raise the final remuneration values but they cover up depreciation and a precariousness of the salaries. This precariousness has become more aggravated because of the great number of teacher employed by temporary contracts. They are called ACTs and their contracts offer the same remuneration paid to teachers who was approved in public concourse, but ACTs do not make part of the public staff and they cannot upgrade their carriers.
\end{abstract}

Keywords: Basic Education. Public Teaching. Teacher Remuneration

Recebido: 18/01/2012

Aprovado: 14/06/2012 